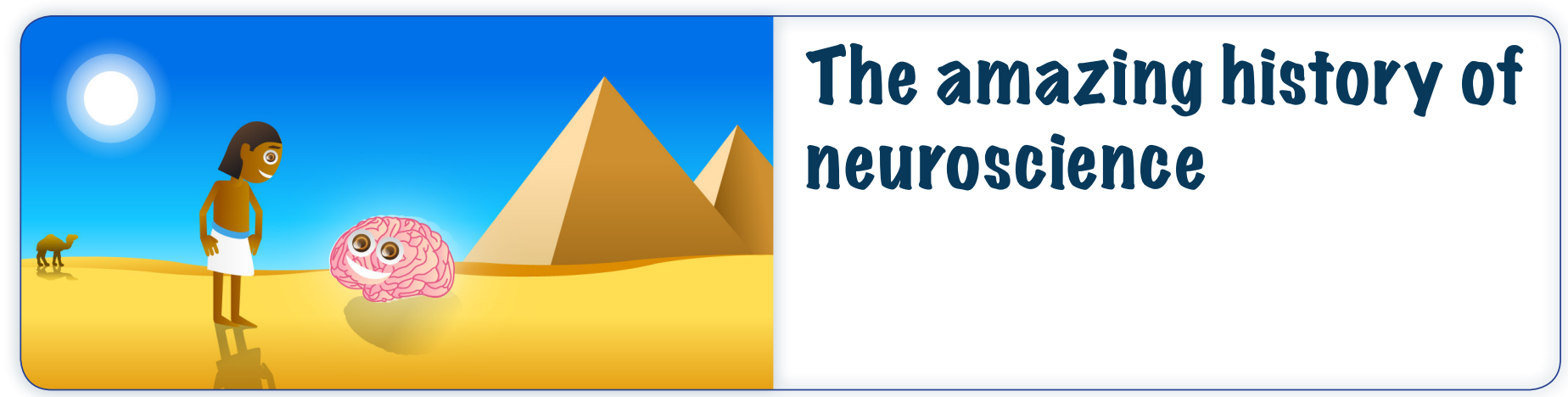

\title{
Stefano Sandrone
}

Institute of Psychiatry, King's College London, London, UK

\section{Reviewed by:}

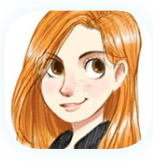

Alma

9 years old
Everything you know is in your brain. For anything you do not know, you can ask the web. However, as you can imagine, in the past, there were no computers and no web at all. Think about people living 3500 years ago, in places where pyramids towered above, instead of the modern buildings you can see around. The lack of explanations about how things worked prompted the ancients to make discoveries and feed their curiosity.
But do not think they were ignorant: in fact, we still wonder how the Egyptians could build the pyramids using their own, rather primitive, technology. They wrote down their knowledge on books (called papyrus scrolls) so that their descendants could acquire benefit from their acquired expertise (Figure 1).

Living safer and healthier was a top priority for the ancients: when they hurt their heads in battle, they used to heal their wounds using the remedies they had discovered on their own. Some of these remedies were recorded on a papyrus now known as Edwin Smyth Papyrus [2]. Interestingly, this is the oldest written evidence of the word brain we have on Earth, and it dates back to 3500 years ago (see Figure 2). Use the hieroglyphics to write the word BRAIN in the blank space!

However, writing the word brain on a papyrus did not solve all the curiosities and questions around it. About 2500 years ago, for example, ancient Greeks wondered whether mind and soul lies in the brain or in the heart. According to the Egyptians, the heart was the most important organ of the body and was the only one that was kept in the corpses during the process of mummification, while the brain was usually removed through the nose.

2000 years ago, namely 500 years after the debate started, Roman physician Galen of Pergamon was sure to have solved the question: it was the brain, not the heart, that was the centre of mental life. However, Galen had to convince the people around him that what he had discovered was true. It was not easy, mostly because people were still anchored to their previous convictions and not so open-minded. Every neuroscientist, just like Galen did, has to carefully observe reality, focus on something that was really interesting, think about how it can work (hypothesis), make a prediction, perform experiments, and interpret the data they get. This way, they can obtain convincing evidence to be shared with others. These steps are the pillars of the scientific method, which is probably the basis of the general way of thinking, 


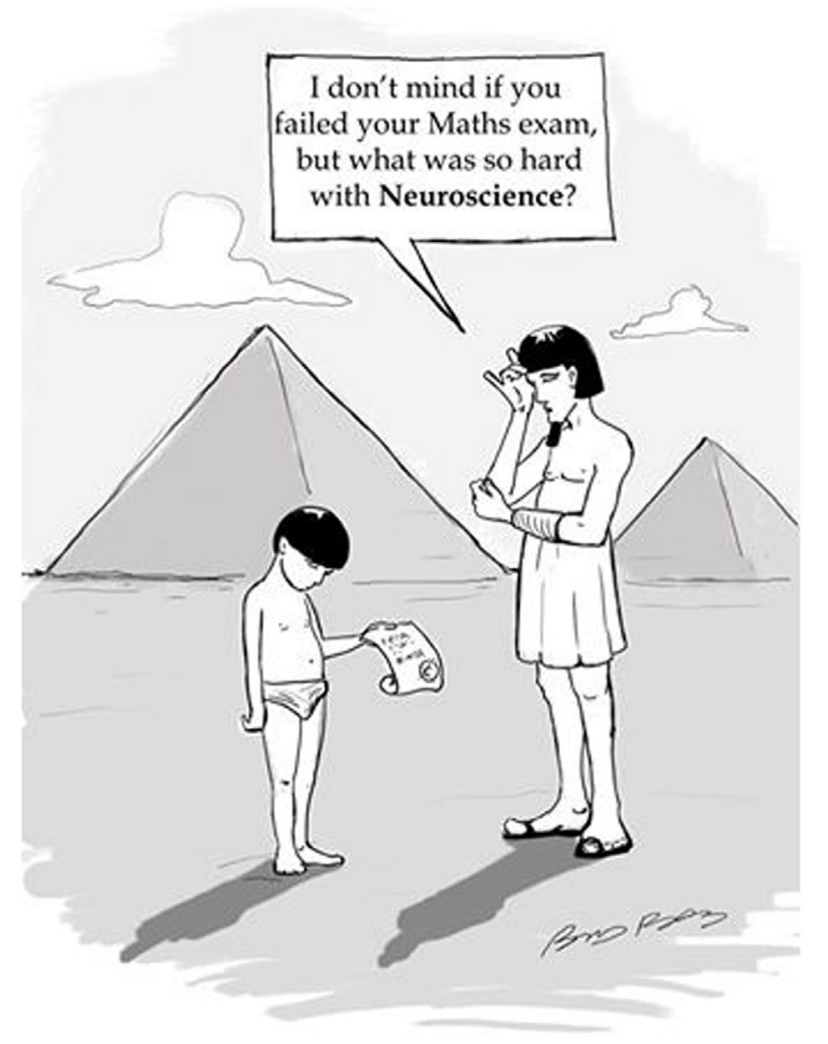

FIGURE 1 -Ancient Egyptian humor [1].

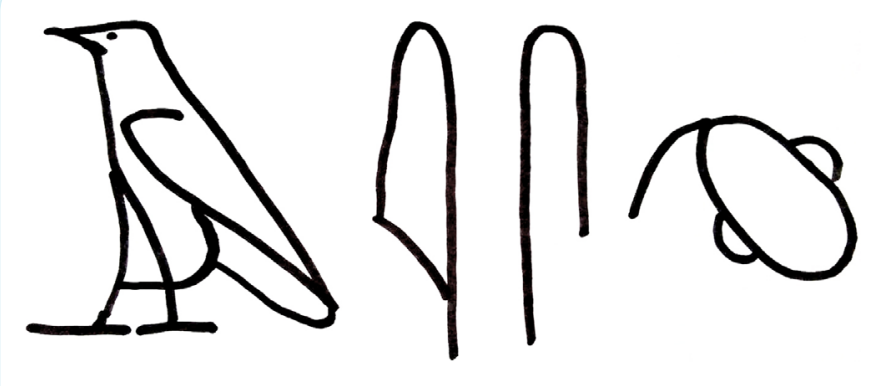

FIGURE 2 - On the top, the word "BRAIN" is written using the hieroglyphics. On the bottom, a blank space where you can try to write the word BRAIN as the Ancient Egyptians did. (available on-line!).

officially introduced only 500 years ago when René Descartes and Thomas Willis finally stated that the brain had won the debate over the heart. A trace of the long-lasting argument between brain vs. heart is still present in a linguistic expression we use: in fact, to say that we can memorize and learn something, we say "to learn by heart," while it would be more correct, at least from an anatomical point of view, to say "to learn by brain."

After that achievement, new neuroscience questions arose: what is the brain and how is it made? Brain research can be carried out through inspiration and hard work, mistakes and chances, collaboration and envy, as well as data you can interpret in different ways. For example, around 130 years ago, the Italian neuroscientist Camillo Golgi invented a new and amazing method to visualize the neurons, which are the cells with which the brain is made.

This method, named the "Golgi technique," after Professor Golgi, allowed researchers to see what you can observe in Figure 3. The black "spots" labeled with capital letters represent the body of the neurons, whereas the blank lines are the connections among them. A similar image was also seen by his Spanish colleague Santiago Ramón y Cajal, who used the Golgi method but drew a different conclusion. In fact, according to Golgi, the brain was a unique network made by huge neurons, whereas Cajal thought it was made by many little interconnected neurons instead. Who do you think was right?

Actually, both of them were right and wrong. Golgi rightly set the technique and Cajal correctly interpreted the data. Even if they were a bit jealous of one another, they shared the Nobel Prize in 1906.

Once the basic structure was established (even if many questions about the structure of the brain are still unanswered), neuroscientists addressed the functions of the brain: How does it work? How does it enable us to sense, feel, think, talk, and remember? Keep in mind that the brain is a complex organ: there may be more neurons in your brain than stars in the starry sky, and neurons are able to communicate with each other faster than a jet. 


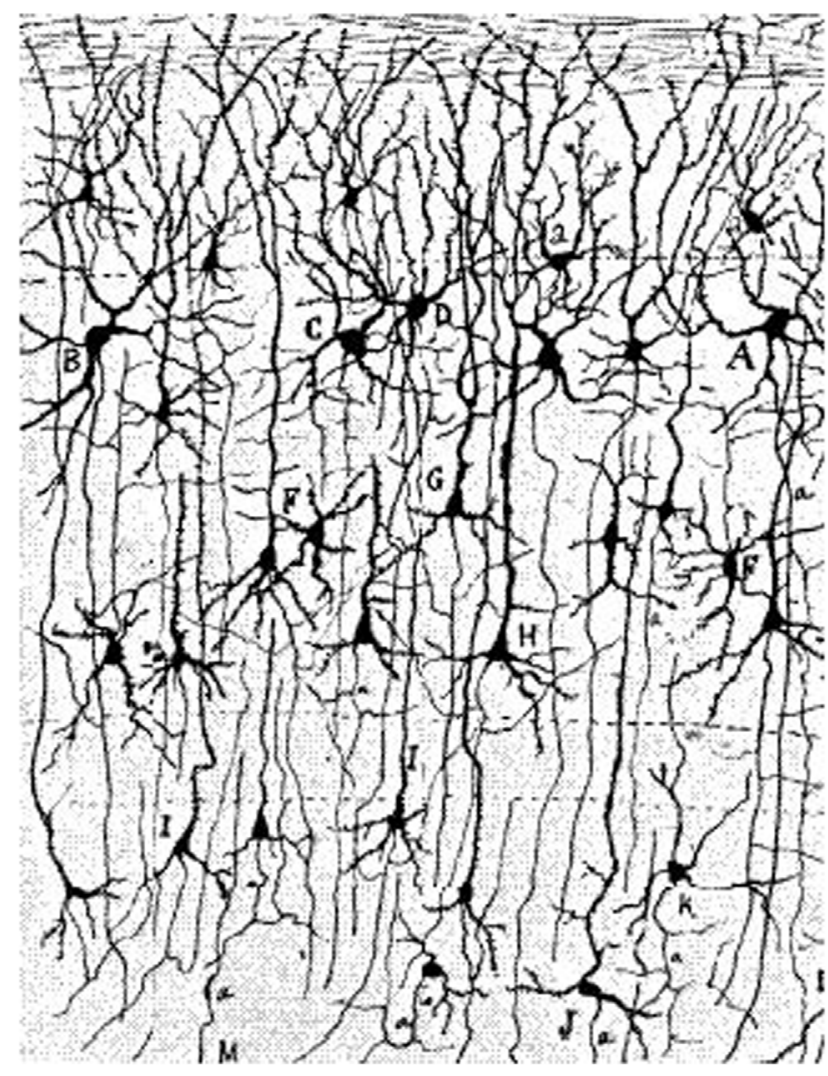

FIGURE 3 -This is what Golgi and Cajal could see.

A unique network made up of huge neurons, or many little interconnected neurons?

To simplify this complexity, teams of neuroscientists, in the twentieth century, began to investigate not only the human brain but also simpler organisms in parallel. The study of giant squid taught neuroscientists how neurons "talk" to each other in the brain (the "chat" they have is called a synapse); large sea slugs helped us to discover how memories can be stored and retrieved; frogs and cats explained how the world around us can be seen; chickens, mice, and monkeys showed how the nervous system develops as we grow; jellyfish and green algae allowed us to visualize parts of the nervous system. Furthermore, because the brain is a living organ, it gets old and, unfortunately, ill. One of the greatest contemporary challenges is to cure mental diseases, which affect a large and increasing portion of the population worldwide.
So, where we are heading nowadays? It is difficult to state. (Neuro)science is more similar to Linking the Dots without a given solution, rather than to a straight and well-defined line. In science, just like in sports - and more generally in life - when you reach the limits, you try to break the boundaries, to reach new frontiers. You might think we already know everything, but I am happy to tell you that this is not true. We know just a part of how the brain works.

We could not say precisely how many things are yet to be discovered. Is the best yet to come? Probably, yes. In any case, we will discover it together, living and studying. By heart, "by brain" and with passion. And, above all, enjoying ourselves.

\section{A SHORT NEUROSCIENCE GLOSSARY FOR YOUNG MINDS:}

Experiment a procedure to follow to state whether a hypothesis is valid or not and, more generally, to reply to (scientific) questions.

Hieroglyphics the writing system used by the Ancient Egyptians that you can see pictured in Figure 2. Curiously, their letters are more similar to images than to the letters we are used to read nowadays!

Hypothesis it is an explanation you can propose to explain something that happened; it can be tested performing an experiment.

Nobel Prize an international award given every year to outstanding scientists. It is regarded as the most prestigious award available in the scientific field.

Papyrus a thick paper-like material produced from a plant named...papyrus!

Synapse a "chat" among neurons. How do synapses work on the brain? We have some answers, but maybe you can study them and make amazing discoveries! 


\section{ACKNOWLEDGEMENTS}

Many thanks to Bruno Borgiani for having drawn Figure 1. Figure 2 is taken from http://faculty. washington.edu/chudler/papy.html and Figure 3 from http://www.cs.utexas.edu/ novak/cs381k418.html

\section{REFERENCES}

1. Borgiani, B. 2006. CS 381K Artificial Intelligence: Lecture Notes. Available at: http://www.cs.utexas.edu/ novak/cs381k418.html

2. Kandel, E. R., Schwartz, J. H., and Jessell, T. M. 2012. Principles of Neural Science. New York: McGraw-Hill.
Submitted: 13 October 2013; Accepted: 30 October 2013; Published online: 13 November 2013.

Citation: Sandrone, S. (2013). The amazing history of neuroscience. Front. Young Minds. 1:14. doi: 10.3389/frym.2013.00014

Copyright (C) 2013 Sandrone. This is an open-access article distributed under the terms of the Creative Commons Attribution License (CC BY). The use, distribution or reproduction in other forums is permitted, provided the original author(s) or licensor are credited and that the original publication in this journal is cited, in accordance with accepted academic practice. No use, distribution or reproduction is permitted which does not comply with these terms. 


\section{frontiers FOR YOUNG MINDS}

\section{REVIEWED BY:}

\section{Alma, 9 years old}

I am in third grade. I was born in San Francisco and now live on the East Coast with my parents and little sister. I love to read the Katie Kazoo books and am obsessed with Harry Potter. I am excited to be involved in Neuroscience for young minds because I am interested in the way the brain works and what we can find out.
AUTHOR

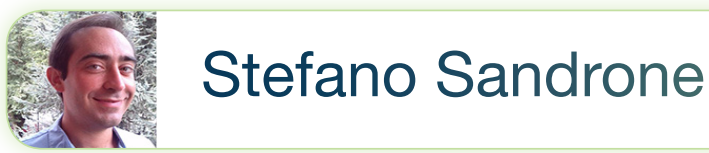

(Canelli, Italy, 1988) loves arts, sports - especially football - and, of course, neuroscience and the history of brain research! After having studied in Milan and Zurich, he recently joined King's College London. He investigates neuroplasticity, namely how the brain changes over time, looking inside it with amazing tools called "neuroimaging." 